\title{
A TEACHER-BASED CHECKLIST FOR THE ASSESSMENT OF STUDENT LEARNING AND DEVELOPMENT
}

\author{
DAVID WILLIAM OBORNE \\ Simon Fraser University \\ YING CHENG HOH \\ Private Practice \\ LYNDA RUTH HUTCHINSON \\ King's College at Western University
}

\begin{abstract}
This paper reports on two studies that evaluated the statistical validity of the Classroom Learning and Development Questionnaire as a universal screening and early identification observation instrument within the North American context. The Classroom Learning and Development Questionnaire was first proposed and tested in Hong Kong in the mid-1990s. It has been used as an integral part of the school procedures in the Hong Kong school system since it was first launched and has spawned a number of intervention programs for students within the Hong Kong Educational Authority.

The Classroom Learning and Development Questionnaire (CLDQ) has been adapted from the Hong Kong study as a Tier I observation instrument to be used in the North American context. Results of the principal component analysis (PCA) in Study $1(N=820)$ extracted six components, which exhibited adequate to high levels of internal consistency. Results of Study $2(N=117)$ indicated statistically significant and negative relationships between the CLDQ subscales and Teacher Rating Form (TRF) (Achenbach, 1991) variables, demonstrating evidence of convergent validity.

Based on the findings of these studies, the authors conclude that the screening protocol does present as a robust instrument capable of supporting screening at a primary prevention level. Based on this study, it is argued that classroom teachers hold a wealth of information concerning each student and that this, when presented in a systematic fashion, leads to greater understanding of individual and group learning needs and may lead to pre-emptive actions which would benefit students' learning trajectories.
\end{abstract}

Keywords: Risk factors; Protective factors; School-aged children; English language learners

David William Oborne, D.W., Cheng Hoh, Y. \& Hutchinson, L.R. (2014). A Teacher-Based Checklist for the Assessment of Student Learning and Development. International Journal of Education Policy \& Leadership 9(4). Retrieved from www.ijepl.org.

\section{Introduction}

The two studies presented in this article are a follow up to a study that was previously completed by the authors in Hong Kong, China (Oborne \& Cheng Hoh, 1996). The aim of the present studies is to test a North American screening protocol based on the well-documented success associated with the authors' work in Hong Kong in the 1990s.
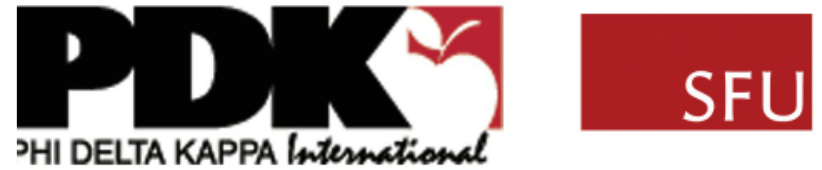

SIMON FRASER UNIVERSITY THINKING OF THE WORLD
At the threshold of the 21st century, Hong Kong and its surrounding territories saw an unprecedented surge in teen suicide. The number of successful suicide attempts and the choice of irreversible methods of self-harm sent shock waves reverberating through the whole region (Breakthrough, 1993). Wong and Lee (2005), as well, reported the phenomenon in the following excerpt:

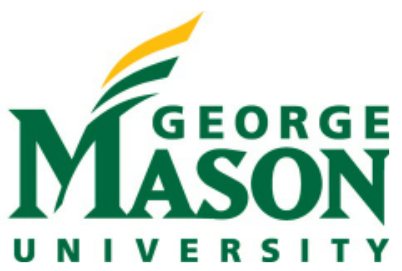


In the early 1990's, with the return of Hong Kong's sovereignty to China in 1997 looming, the Hong Kong government expected a large number of young immigrants to come to the island from Mainland China. Public attention to the needs of youth at risk was greatly increased during the time after a chain of alarming events, including the rising rates of suicide. ... (p. 315)

The Department of Welfare and Social Services in Hong Kong invited proposals to help deal with the new and troubling social trend among Hong Kong youth. Having just completed a highly successful intervention project for marginalized refugee youth in Winnipeg (Oborne \& Cheng Hoh, 1990), the authors were invited by Breakthrough, a youth-serving organization in Hong Kong, to submit a study proposal to the Hong Kong government. Coined the Understanding the Adolescent Project (UAP), the project was rooted in the primary prevention and early identification framework for mental health (Albee, 2004; Kessler \& Albee, 1975). The authors devised a screening protocol as the starting point for early identification of risk and protective factors for youth in school systems. Under the auspices of Breakthrough, the Canadian team, with members drawn from educational administration, school psychology, and adolescent psychiatry, joined with members of the Chinese University of Hong Kong's Centre for Clinical Trials and Epidemiological Research to collaborate over the following two years to establish the foundation for the UAP.

The concept of primary prevention and the early screening instruments-namely, the Hong Kong Student Information Form (student edition) and the Hong Kong Student Information Form (teacher edition) - are now an integral part of the Hong Kong Education system. The UAP continues to play a prominent role to inform social policy and educational practices (Education Bureau, Hong Kong, 2013).

The formal report of the Hong Kong project, "Understanding the Adolescent Project: Research Report," was submitted to a joint committee representing the departments of health, welfare and social services, and education in September 1996 (Oborne \& Cheng Hoh, 1996). The Hong Kong study and its resulting program initiatives have been well documented since that initial report was submitted (Lau et al., 1999; Wong \& Lee, 2005). A review of the Hong Kong Education website finds references to ongoing use of the screening protocols and associat- ed programs to the present day (Education Bureau, Hong Kong, 2013).

The UAP involved 3,500 students drawn from 50 secondary schools in Hong Kong, which were selected as a random stratified sample (Breakthrough, 1996). Secondary schools in Hong Kong were banded in five academic groupings, with students writing screening tests at the end of elementary in order to gain admission to the secondary schools of their choice. All students in the sample were screened using the instruments we authored. Half of the sample was also screened using the Achenbach Child Behaviour Checklist (see Achenbach, 1991), and a further 10 percent sample was subjected to the Diagnostic Screening Interview for Children found in the DISC-2.3 Manual for Children (American Psychiatric Assn., 1994). The Department of Epidemiology and Clinical Trials at the Chinese University of Hong Kong conducted the statistical analysis, under the supervision of its director, Dr. Joseph Lau. Dr. Kelly Lai, a child psychiatrist in Hong Kong, also supported this project as a part of the management team, and her students carried out the Diagnostic Statistical Manual interviews (Oborne, 1996).

Since the UAP study, we have seen a continuing interest in this screening measure in Hong Kong. In 2000, the first Beijing-appointed Chief Executive in Hong Kong, Mr. Tung Chee Hwa, delivered a policy address to the Hong Kong Legislative Council entitled "Serving the Community, Sharing Common Goals" (Tung Chee Wa, 2000), in which he established one social worker position in each secondary school as a result of this research. This declaration meant the addition of approximately 450 social worker positions, a major investment in education. Much subsequent work has been completed on developing intervention strategies for dealing with the results of UAP screenings. As recently as April 2013, there have been references in Hong Kong (Education Bureau, Hong Kong, 2013) to the ongoing work and school-based programs that have come out of this initial research project. Currently, the UAP is an integral part of the school system in Hong Kong (Education Bureau, Hong Kong, 2013).

The work completed in developing the screening measure in Hong Kong has also been previously reported in an article for the Canadian Psychiatric Association (Compte et al., 1997) and has been the topic of several conference presentations in Canada as well as China (Oborne, 1999, 2000, Oborne \& Cheng Hoh, 2000).

In recent decades, school systems in British Columbia's Lower Mainland have experienced expo- 
nential growth in the diversity of language and cultural groups in the urban school environment. Increasingly, the classroom teacher is called upon to address diverse student needs in academic, linguistic, cultural, emotional, and behavioural spheres (Statistics Canada, 2006). In 2006, we initiated a validation study of the Classroom Learning and Development Questionnaire (CLDQ) screening form in the Canadian public school context.

The present studies assess the statistical validity of the Classroom Learning and Development Questionnaire (CLDQ) as a Tier I observation instrument within the North American context. We then compare the properties of the CLDQ are compared to the Teacher Report Form (TRF) of the Achenbach system of empirically based assessment (ASEBA), an internationally validated clinical instrument.

\section{Risk and Protective Factors}

The development of the CLDQ has been based on a number of studies reporting on risk and resiliency factors affecting children's development. The risk and resiliency literature has accumulated evidence that individual and contextual risk and protective factors influence children's social, emotional, and academic learning trajectories (Cummings \& Davies, 2002; El-Sheikh \& Whitson, 2006; Fraser, Day, Galinsky, Hodges, \& Smokowski, 2004). Compte (1997), in her review of the literature for the UAP, reviewed risk and protective factors described in the research literature (Avison, 1996; Doll \& Lyon, 1998; Gladstone \& Kaslow, 1995; Hamre \& Pianta, 2005; Hetherington \& Stanley-Hagan, 1999; Hawkins et al., 1999; Rutter, 2001; Rutter \& Quinton, 1975, 1984; Offord, Alder, \& Boyle, 1986; Waller, 2001; Werner \& Smith, 1989, 1992). Studies indicate that children who experience more risk factors tend to have poorer cognitive, language, literacy, and social and emotional skills, and that they tend to experience lower academic learning and achievement (Burchinal, Roberts, Zeisel, \& Rowley, 2008; Rutter, 2001; Rutter \& Quinton, 1975; Sameroff, Seifer, Zax, \& Barocas, 1987).

Similarly, Compte (1997) cited researchers who have identified protective factors that promote adaptive social and emotional development and academic learning in the presence of risk (Amato, 2004; Burchinal, Roberts, Zeisel, \& Rowley, 2008; Catalano, 2010, 2006; Hamre \& Pianta, 2005; Hsieh \& Shek, 2008; Werner \& Smith, 1989, Hawkins, 1992). These studies have linked protective factors-such as forming secure attachments, functioning autonomously, and moving toward self- regulation during the first three years of life within elementary school-to children's math and reading achievement (Rutter, 1979; Rutter \& Quinton, 1975; Rae-Grant, Thomas, Offord, \& Boyle, 1989; Teo, Carlson, Mathieu, Egeland, \& Sroufe, 1996). Other studies confirm these findings, indicating that risk and protective factors are associated with children's academic learning as early as elementary school (Burchinal et al., 2008; Smokowski, Mann, Reynolds, \& Fraser, 2004; Shumow, Vandell, \& Posner, 1999). Taken together, the research indicates that studying children's exposure to risk and protective factors during elementary school is important for understanding their social and emotional development and academic learning.

\section{Past Research}

Research to date has focused primarily on the identification of social, emotional, or academic risk, or on the prevalence of these risk factors among general populations of students. Most of the research reported in the literature has been in the form of clinical assessments on children and students deemed at risk. This research has been predominantly focused on "at-risk" behaviours or conditions. The current research being reported here, in contrast to previous research included factors associated with healthy child development, looking at resiliency as a vital part of the student's ability to learn.

Other tools, such as the Early Development Index and the Middle Years Development Index, have provided much helpful information concerning student achievement, set against a background of what may be reasonably expected given the social milieu in which their schools find themselves embedded. While these measures are quite helpful in dealing with populations of students, they are not intended to be descriptive of individual areas of needs or strengths. The instrument assessed in this study was developed, based on the existing research, to be a classroom-screening tool for use by teachers, with the aim of providing supports according to the profile of strengths and weaknesses exhibited by each student.

The current research is situated in a newer and growing literature, one that sees assessment as a dynamic interplay between intervention and assessment of the response to that intervention. As such, the literature describes the complex interplay between student attributes, classroom interventions, and analysis of integration of new learning. 
There are several limitations within previous research on risk and protective factors. First, there has been a preponderance of research involving clinically "at-risk" children in middle and high school, in comparison with research on typically developing elementary and middle school children. An important limitation of such measures is that, while they provide indications of social, emotional, and academic weaknesses, they do not identify social, emotional, and academic resiliency or well-being. Nor has previous research targeted general populations. Clinical measures are employed at the stage where learning or social/emotional issues need to be defined; as such, they are designed to deal with secondary prevention rather than primary prevention activities. More research is warranted to design and administer psychometrically sound measures that can be used with general populations of students as a means of providing early, cost-effective screening for behaviours indicative of social, emotional, and academic risk or weakness, and for identifying social, emotional, and academic behaviour patterns. Finally, existing classroom-based measures administered to all students do not provide insight into a child's proficiency in the dominant language in school and/or in their home language, which may have an impact on the student's social, emotional, and academic success (Cummins, 2000; Roessingh, 2004; Roessingh \& Elgie, 2009).

In contrast to existing research, the goal of this research is to give classroom teachers who already provide support personnel and other decision makers standardized, validated information concerning student attainment for clinical diagnosis and intervention a comprehensive, valid, standardized early screening tool for primary prevention early identification. The goal of this research is to organize knowledge of students' development, which heretofore has been held anecdotally by teachers and organize it into broader concepts of social and emotional development trajectories. Data, which have until now been used only in narrative, descriptive formats, may be used quantitatively as preliminary active intervention signals for schools and those professionals supporting them. Our research perspective establishes teachers as partners in providing academic and student support services.

The perspective of the studies presented in this article sees teachers as the professionals who provide early identification and support in the school setting. This screening instrument/CLDQ provides a new starting point in supporting students in the school system and in their continued so- cial/emotional development as they mature. As such, this research is faithful to the concept of early identification and intervention based on risk and protective literature in student learning and social/emotional development.

Previous findings indicate that early intervention and prevention programs aimed at reducing children's exposure to risk can be effective in the short and long term (Hawkins, Catalano, Kostermann, Abbott, \& Hill, 1999). These findings underscore the importance of identifying risk and protective factors at early phases or stages of development, and of mitigating children's exposure to risk by increasing protective factors (Dryfoos, 1998; Hamre \& Pianta, 2005; Lane, Beebe-Frankenburger, Lambros, \& Pierson, 2001; Leventhal \& Brooks-Gunn, 2000; Rouse \& Fantuzzo, 2009; Walker, Stiller, Severson, Feil, \& Golly, 1998).

\section{Instrument Development}

In its original form, the CLDQ began as a teacher observation form, developed by consulting with professionals working within Winnipeg School Division No. 1 in Winnipeg, Manitoba, Canada. The goal was to enable teachers to record observations of student behaviour in a succinct fashion so they could provide their observations to professionals assisting in addressing individual students' learning difficulties. An expert panel consisting of teachers, speech/language pathologists, psychiatrists, psychologists, social workers, reading specialists, and community workers was convened to consult on the development of this measure. The resultant form described each student in a class so that observations would be grounded in the typical patterns of classroom behaviour. This context provided a measure of objectivity and balance for the description of the students in question. The form was given to a panel of teachers, school administrators, and social workers to adapt it to the Hong Kong experience. Lastly, the form was refined and adapted to the present studies with input from a Canadian reference panel of teachers and school principals.

\section{Research Goals}

The overall goal of the present studies was to establish whether or not the CLDQ could be used in the North American context as an early universal screening measure in the assessment of students' social, emotional, and academic strengths and weaknesses. 
Two studies were conducted to address our research goal. The first study explored two research questions:

1. What is the reliability of the CLDQ as compared to a standardized measure, i.e. the Achenbach Teacher Rating Form (Achenbach, 1991)?

2. What are the relationships between the components extracted from the CLDQ?

The second study posed one research question: What is the relationship between the CLDQ scales and the Achenbach Teacher Rating Form (TRF) measure?

To be successful, we would expect that higher scores on the CLDQ and each of the subscales would be significantly and negatively associated with lower scores on the TRF. Similarly, we expected that teachers' ratings of children's social and emotional development and academic learning on the CLDQ would correlate with their ratings of children on the items that comprise the TRF.

\section{Study I}

In this study, 32 elementary school teachers from 17 schools provided data on 820 Grade 5 children (393 males; 427 females) from a large suburban school district in Vancouver, BC. The average age of children in this study was 10.54 years of age $(S D=0.50$ years). The school district from which data were gathered serves the full range of socio-economic status (SES), learning needs, and cultural backgrounds (approximately 20 percent of children spoke a language other than English). A total of 17 schools out of 49 operating in the school district were selected for this study. The selection process enabled a stratified sample of schools to be chosen, based on the socio-economic measures derived from the Understanding the Early Years study conducted by Human Resources Development Canada, which began in 1999 (SRDC 2005, Grant, E. 2003). The Early Years Study had assigned a relative SES ranking to each school in the district. The schools chosen were representative of that range of schools based on their ranking.

The CLDQ is a 37-item, teacher-questionnaire measure, which was administered in paper and pencil form. The purpose of the measure is to assess factors related to typically developing children's social development and learning. Teachers were asked to complete one CLDQ for each child in the classroom. The questionnaire solicited a response for each statement using a five-point Likert scale, where $1=$ never $/$ no, 2 occasionally, 3 = average, $4=o f-$ ten, and $5=$ always. Items for the CLDQ were developed by (a) visiting schools and conducting focus groups with teachers and administrators, (b) reviewing current literature and measures that examine risk and protective factors, and (c) interviewing and meeting with professionals working in the education, social services, and health sectors to confirm that items on the CLDQ were suitable for schools.

Data for Study I were collected over a period of approximately 12 weeks. A letter from the school district, along with a letter from the school principal, was sent to eligible teachers and children's parents, informing them of the study and their option to participate. After consent was received from teachers and parents, researchers visited participating classrooms to provide teachers with a class set of CLDQ forms. Teachers were asked to complete one form for each student in the class.

Results of the principal component analysis (PCA) indicated that when item scores on the CLDQ were analyzed, six components could be extracted with commonality values ranging from .4 to .93 , satisfying the first criterion for our analysis. The Kaiser-Meier-Olkin (KMO) test of sampling adequacy was computed at .942 (excellent), and Bartlett's test of sphericity was, $\chi^{2}(66)=26829.41, p<.001$, indicating that PCA was an appropriate method of analysis for these data. The rotated component loadings displayed in Table 2 show that items tended to load highly on one component, with load values that ranged from .4 to .9 , satisfying the second criterion for this analysis.

The results from the component analysis are summarized in the Table 1. In total, we achieved explanation of $72.23 \%$ of the variance among the variables, satisfying our goal of explaining at least 70 percent of the variance among the variables. The eigenvalues-greater-than-one criterion was satisfied in extracting each of the components in the analysis, and visual inspection of the scree plot supported the

Table 1. Extracted Components and Corresponding Items

\begin{tabular}{|l|c|c|c|l|}
\hline Component & Number of Items & Eigenvalue & \% of Variance & Items \\
\hline 1. Classroom learning/achievement & 11 & 13.61 & 36.79 & $1,8,15,16,17,18,19,22,23,25,26$ \\
\hline 2. Disposition & 4 & 4.99 & 13.48 & $3,4,5,6$ \\
\hline 3. Proficiency in English & 5 & 3.33 & 9.00 & $27,29,31,33,34$ \\
\hline 4. Respect/compliance & 11 & 1.78 & 4.82 & $2,7,9,10,11,12,13,14,20,21,24$ \\
\hline 5. Educational support/intervention & 3 & 1.59 & 4.30 & $35,36,37$ \\
\hline 6. Home language proficiency & 3 & 1.42 & 3.84 & $33,35,37$ \\
\hline
\end{tabular}


Table 2. Pattern Matrix from the Principal Components Analysis $(N=820)$

\begin{tabular}{|c|c|c|c|c|c|c|}
\hline Item & 1 & 2 & 3 & 4 & 5 & 6 \\
\hline 1 & .890 & & & & & \\
\hline 2 & & & & 0.644 & & \\
\hline 3 & & 0.849 & & & & \\
\hline 4 & & 0.697 & & & & \\
\hline 5 & & 0.857 & & & & \\
\hline 6 & & 0.799 & & & & \\
\hline 7 & & & & 0.819 & & \\
\hline 8 & .863 & & & & & \\
\hline 9 & & & & 0.658 & & \\
\hline 10 & & & & 0.731 & & \\
\hline 11 & & & & 0.852 & & \\
\hline 12 & & & & 0.843 & & \\
\hline 13 & & & & 0.826 & & \\
\hline 14 & & & & 0.786 & & \\
\hline 15 & .857 & & & & & \\
\hline 16 & .797 & & & & & \\
\hline 17 & .858 & & & & & \\
\hline 18 & .808 & & & & & \\
\hline 19 & .897 & & & & & \\
\hline 20 & & & & 0.861 & & \\
\hline 21 & & & & 0.796 & & \\
\hline 22 & .848 & & & & & \\
\hline 23 & .447 & & & & & \\
\hline 24 & & & & & 0.763 & \\
\hline 25 & & & & 0.666 & & \\
\hline 26 & .788 & & & & & \\
\hline 27 & & & 0.940 & & & \\
\hline 28 & & & & & & 0.943 \\
\hline 29 & & & 0.930 & & & \\
\hline 30 & & & & & & 0.795 \\
\hline 31 & & & 0.964 & & & \\
\hline 32 & & & & & & .956 \\
\hline 33 & & & .936 & & & \\
\hline 34 & & & .469 & & & \\
\hline 35 & & & & & .848 & \\
\hline 36 & & & & & .792 & \\
\hline 37 & & & & & .646 & \\
\hline
\end{tabular}

retention of six meaningful components. Overall, results of the PCA indicate that six components related to students' social and emotional development and academic learning could be extracted from the data gathered by the CLDQ ${ }^{1}$.

To assess the reliability of the CLDQ, Cronbach's alpha of internal consistency was calculated for the scores on the six components (subscales) and for the total. It is important to recognize that Cronbach's alpha provides a lower bound estimate of reliability within a scale. Within the literature, researchers indicate that the internal consistency of scales should be at least .70 to justify the summation scales (Huck, 2008). The item scores (see Table 1) that comprised the 10-item classroom learning/achievement subscale were analyzed, and results indicated a high Cronbach's alpha of .94 . The scores that comprised the disposition subscale were analyzed and produced 
Table 3. Descriptive Statistics for the CLDQ Overall Score and Subscale Scores $(N=820)$

\begin{tabular}{llll}
\hline Variable & $M$ & $S D$ & Min to Max \\
\hline Classroom learning/achievement & 3.61 & .77 & $1-5$ \\
Disposition & 3.09 & .94 & $1-5$ \\
Proficiency in English & 4.50 & .81 & $1-5$ \\
Respect/compliance & 4.04 & .80 & $1-5$ \\
Educational support/intervention & 4.03 & .99 & $1-5$ \\
Home language proficiency & 4.39 & .77 & $1-5$ \\
Total & 3.93 & .63 & $1.43-5$ \\
\hline Note: The rating scale teachers use to complete items on the CLDQ is a five-point Likert scale with endpoints ranging from \\
1 (never) to 5 (always).
\end{tabular}

a Cronbach's alpha of .85 , indicating a high level of internal consistency among the scores. The proficiency in English subscale had five items and a Cronbach's alpha value of .90 , demonstrating high internal consistency. The 11-item respect /compliance subscale had a Cronbach's alpha of .93, demonstrating that scores displayed high internal consistency. Educational support/intervention had a Cronbach's alpha of .69 for the four items that comprised the scale. The three-item home language proficiency had a Cronbach's alpha of .89. The Cronbach's alpha value for the entire 38 -item scale was computed at .94, indicating a high level of internal consistency.

We created the variables for classroom learning and achievement, disposition, proficiency in English, respect/compliance, educational support/intervention, home language proficiency, and total scores component and dividing that sum by the number of items that comprised each scale. Descriptive statistics for the average scores of classroom learning /achievement, disposition, proficiency in English, respect/compliance, educational support /intervention, home language proficiency, and their overall or total scores of social and emotional development and academic learning are presented in Table 3. Overall, teachers rated children as having a relatively high level of adjustment across these subscales and overall.

To answer the second research question concerning the relationship between the CLDQ components, we computed a series of Pearson product-moment correlations, found in Table 4, to examine the relationships between the CLDQ variables. Effect sizes for the correlations should be considered using Cohen's (1992) criteria where (a) $r=0.1$ (small effect), (b) $r=0.3$ (medium effect), and (c) $r=0.5$ (large effect). Results indicate that nearly all the relationships among the variables were statistically significant and positive. Specifically, the classroom learning and achievement subscale was significantly and positively related to each of the six subscale variables: namely, classroom learning/achievement, disposition, proficiency in English, respect/compliance, educational support/intervention, home language proficiency, and the total score of social and emotional development and academic learning. Also, no statistically significant relationship was observed between respect/compliance and disposition. The statistically significant relationships observed between classroom learning and achievement and the subscales of disposition, proficiency in English, respect/compliance, educational support/intervention, and home language proficiency had medium to very large effect sizes, demonstrating that children's classroom learning and achievement are related to disposition, their abilities to read, write, and speak English, their displays of respectful and compliant behaviour in class, their lack of reliance on assistance or interventions in school, and their abilities to communicate in their home language.

Table 4. Intercorrelations among the Variables $(N=820)$

\begin{tabular}{lcccccccc}
\hline Variable & 1 & 2 & 3 & 4 & 5 & 6 & 7 & 8 \\
\hline Classroom learning/achievement & 1 & - & - & - & - & - & - & - \\
Disposition & $.31^{* *}$ & 1 & - & - & - & - & - & - \\
Proficiency in English & $.45^{* *}$ & $.28^{* *}$ & 1 & - & - & - & - & - \\
Respect/compliance & $.70^{* *}$ & $-.08^{*}$ & $.32^{* *}$ & 1 & - & - & - & - \\
Educational support/intervention & $.64^{* *}$ & $.32^{* *}$ & $.37^{* *}$ & $.42^{* *}$ & 1 & - & - & - \\
Home language proficiency & $.21^{* *}$ & $.13^{* *}$ & $.51^{* *}$ & $.15^{* *}$ & $.16^{* *}$ & 1 & - & - \\
Total & $.92^{* *}$ & $.36^{* *}$ & $.63^{* *}$ & $.80^{* *}$ & $.72^{* *}$ & $.38^{* *}$ & 1 & - \\
\hline
\end{tabular}

Note: $* * p<.01, * p<.05$ 


\section{Discussion}

Study 1 explored the structure of the CLDQ, which was designed to assess individual-level risk and protective factors related to typically developing children's social and emotional development and academic learning. Results indicated that six components could be extracted: namely, classroom learning/achievement, disposition, proficiency in English, respect/compliance, educational support/ intervention, and home language proficiency. The results of Study 1 indicate that the classroom learning/achievement subscale contains nine items to measure whether a child is managing learning tasks independently and whether a child is motivated to learn and to achieve academically. In fact, research has demonstrated that children's motivation for learning and their abilities to manage learning tasks independently are related to children's learning in school (see Meece, Anderman, \& Anderman, 2006 for a review). Consistent with the literature, our data indicate that items related to a child's classroom learning and achievement are meaningful for studying risk and protective factors. Results indicate that the disposition subscale contained four items that assess a child's social disposition in the classroom, such as their confidence, social temperament, and activity in the classroom. Research has demonstrated that children who display self-efficacy and who are outgoing and friendly tend to do better on academic achievement tests (Burchinal, Peisner-Feinberg, Pianta, \& Howes, 2002). Research has also demonstrated that children who effectively control affect achieve academically (Graziano, Reavis, Keane, \& Calkins, 2007). The data from our study indicate that the items related to students' temperament and disposition are importantly related to students' social and emotional development and academic learning.

Our study results indicate that the proficiency in English component contained four items, such as a child's written and oral communication in English. Previous research has shown that language deficits have an impact on children's learning and achievement in school (Miller, 2009). Our data suggest that this is a meaningful factor to consider when examining a student's overall profile of risk and protective factors. Results demonstrated that the respect/compliance subscale contained 11 items, including how well students got along with and behaved toward their peers and their teacher. Research has indicated that children who engage in respectful, pro-social behaviour and who comply with teachers' requests are well-liked by their teachers and do better in school (Wentzel 1993a, 1993b). Our data provide evidence of the importance of students' engagement in pro-social/compliant behaviour in school. The educational support/intervention component contained three items that described the amount of support and/or intervention students need inside and outside the classroom. Understanding the level of support/intervention a student requires may provide additional insight into a student's overall profile of risk and protective factors. Finally, the home language proficiency subscale contained three items. Studies indicate that strong academic language skills in one's native language are associated with successful second language learning and academic achievement (Thomas \& Collier, 2002). Furthermore, researchers have emphasized that children's literacy skills in their first language transfer to a second language (Cummins, 2000; Roessingh \& Elgie, 2009). Our data indicate that insight into a child's native language learning is also meaningful for generating an overall understanding of a child's risk and protective factors related to their social and emotional development and academic learning in school.

In conclusion, data from Study 1 allowed us to extract six continuous risk/protective factors from the CLDQ. Generally, the subscales/components displayed a reasonably high level of internal consistency, and nearly all of them had statistically significant and positive relationships to each other, with primarily medium to large effect sizes.

\section{Study II}

In Study II, 25 teachers provided data on 117 children (65 males) over a period of three years, from 2005-2008. Approximately 87 percent of children were in grade 5; 9 percent were in grade 4, and 4 percent were in grade 2 . The average age of participants was 10.87 years $(S D=1.67$; range $6-12$ years). The school district where data were gathered was the same as in Study 1. Approximately 71 percent of the cases that comprised this sample were randomly selected from the larger sample in Study 1. was drawn from data provided by teachers as part of children's educational evaluations.

The CLDQ described in Study 1 was administered in Study 2. The classroom learning and achievement subscale contained 11 items and Cronbach's alpha was computed at .96 , indicating a high level of internal consistency among the scores on this subscale. The disposition subscale contained 
four items, and Cronbach's alpha was computed at .87. The proficiency in English subscale had five items, and Cronbach's alpha was computed at .87. The compliance subscale contained 11 items, and Cronbach's alpha was computed at .94 , indicating a high level of internal consistency. The educational support/intervention subscale was comprised of five items and had a reliability coefficient of .67 , indicating acceptable levels of internal consistency. The home language proficiency subscale contained three items with scores and had a Cronbach's alpha of .88, demonstrating high internal consistency. Finally, the total or overall score of social/emotional development and academic learning contained all 37 items and had a Cronbach's alpha value of .95 .

\section{Achenbach Teacher's Report Form}

The Achenbach Teacher's Report Form, or TRF (Achenbach, 1991), is a 113-item, paper and pencil measure that has been developed as a clinical tool used in the assessment and diagnosis of DSM-IV emotional and behavioural childhood disorders. Its purpose in Study 2 was to provide a measure of convergent validity for the CLDQ. The TRF contains 10 sections, in which teachers provide demographic information as well as anecdotal information and ratings about the child's academic background and academic progress. Items on the TRF measure two domains of psychopathology: externalizing behaviours (behavioural disorders) and internalizing behaviours (emotional disorders). Within these two domains of psychopathology, items can be aggregated to examine eight subscales: namely, withdrawn/depressed, somatic complaints, anxious /depressed, social problems, thought problems, attention problems, delinquent behaviour, and aggressive behaviour. Teachers rate children's behaviour on this form using a three-point scale, where $0=n o t$ true, 1 = somewhat or sometimes true, and $2=$ very true or often true. Scores for each of the TRF subscales are computed by aggregating item scores (see the Achenbach \& Rescorla manual, 2001). Our purpose in employing the TRF was to use it as a measure of convergent validity for the CLDQ. That is, we wanted to ascertain whether teachers' ratings on the CLDQ correlated with those of the TRF, such that high scores for children's social and emotional development and academic learning on the CLDQ would have significant and negative correlations with low scores on the TRF.

\section{Procedures}

For Study 2, data collection was completed in two phases. In May 2005, we randomly selected a subsample of 150 children from Study 1 and asked their teachers to complete a TRF form for selected children. The return rate on the TRF forms that teachers completed was approximately 100 percent. However, due to incomplete data on the TRF, the subsample was reduced from 150 children to 94 children. From September 2006 to June 2008, we collected teachers' ratings of an additional 23 children.

Table 5. Descriptive Statistics for the CLDQ and TRF Variables $(N=117)$

\begin{tabular}{lccc}
\hline Variable & $M$ & $S D$ & Min to Max \\
\hline Classroom learning/achievement & 3.58 & 1.06 & $1.27-5$ \\
Disposition & 3.13 & 1.04 & $1-5$ \\
Proficiency in English & 4.29 & 0.96 & $1.4-5$ \\
Respect/compliance & 4.09 & 0.85 & $1-5$ \\
Educational support/intervention & 3.95 & 1.04 & $1-5$ \\
Home language proficiency & 4.15 & 0.97 & $1-5$ \\
Total & 3.88 & 0.74 & $2.19-5$ \\
Withdrawn /depressed & 1.81 & 2.42 & $0-10$ \\
Anxious /depressed & 3.36 & 3.92 & $0-17$ \\
Social problems & 1.64 & 2.19 & $0-11$ \\
Thought problems & 0.66 & 1.53 & $0-7$ \\
Attention problems & 10.63 & 11.99 & $0-40$ \\
Delinquent behavior & 1.59 & 2.07 & $0-8$ \\
Aggressive behavior & 3.48 & 5.91 & $0-28$ \\
Externalizing & 5.07 & 7.45 & $0-33$ \\
Internalizing & 5.42 & 5.77 & $0-29$ \\
\hline
\end{tabular}




\section{Results}

Table 5 presents the means and standard deviations for each of the CLDQ and TRF variables. Average scores for each of the six subscales and the average total score for the CLDQ were computed by aggregating item scores and dividing by the number of items that comprised each subscale. We created total scores for each of the nine subscales on the TRF by summing the item scores that comprised each subscale.

We addressed our research question by computing a series of Pearson product-moment correlations between the six subscale variables and the total score from the CLDQ, as well as the TRF variables of withdrawn/depressed, anxious/depressed, social problems, thought problems, attention problems, delinquent behaviour, aggressive behaviour, and the two overarching domains of externalizing and internalizing behaviour.

Results of the correlations are presented in Table 6 and should be considered in relation to Cohen's criteria for effect size, where $r=0.1$ (small effect), $r$ $=0.3$ (medium effect), and $r=0.5$ (large effect). On the CLDQ, higher item scores indicate high levels of social and emotional development and academic learning, and low scores indicate low levels of social and emotional development and academic learning. In contrast, scores on the TRF are coded so that high scores indicate high levels of maladjustment and low scores indicate low levels of maladjustment. Column 2 indicates that the CLDQ's classroom learning and achievement variable was statistically significantly and negatively correlated with each of the nine subscales from the TRF, with medium to large effect sizes. Column 3 indicates that disposition was statistically significantly and negatively correlated to the withdrawn/depressed and internalizing variables, and positively correlated to the aggressive behaviour and externalizing variables, with small to medium effect sizes. This finding is consistent with research indicating that children who are more outgoing or uninhibited tend to display less behaviour indicative of anxiety, compared with inhibited and socially shy children (Coplan, DeBow, Schneider, \& Graham, 2009). These findings also support research indicating that children who engage in aggressive behaviour tend to display high levels of activity in class (Nagin \& Tremblay, 2001).

Column 4 illustrates statistically significant and negative relationships between the respect/compliance variable and the withdrawn/depressed, social problems, thought problems, attention problems, and delinquent behaviour variables, corresponding to small to medium effect sizes. In other words, children who were proficient in English displayed few behaviours indicative of clinical social/emotional problems or difficulties

Table 6. Intercorrelations between the CLDQ and TRF Variables $(N=117)$

\begin{tabular}{|c|c|c|c|c|c|c|c|c|c|c|c|c|c|c|c|c|}
\hline Variable & 1 & 2 & 3 & 4 & 5 & 6 & 7 & 8 & 9 & 10 & 11 & 12 & 13 & 14 & 15 & 16 \\
\hline $\begin{array}{l}\text { Classroom learning } \\
\& \text { achievement }\end{array}$ & 1 & & & & & & & & & & & & & & & \\
\hline Disposition & $\begin{array}{l}.30 \\
* *\end{array}$ & 1 & & & & & & & & & & & & & & \\
\hline $\begin{array}{l}\text { Proficiency in Eng- } \\
\text { lish }\end{array}$ & $\begin{array}{l}.61 \\
* *\end{array}$ & $\begin{array}{l}.30 \\
* *\end{array}$ & 1 & & & & & & & & & & & & & \\
\hline Respect/compliance & $\begin{array}{l}.72 \\
* *\end{array}$ & $\begin{array}{l}-.12 \\
* *\end{array}$ & .39 & 1 & & & & & & & & & & & & \\
\hline $\begin{array}{l}\text { Educational support/ } \\
\text { intervention }\end{array}$ & .74 & $\begin{array}{l}.29 \\
* *\end{array}$ & .52 & .51 & 1 & & & & & & & & & & & \\
\hline $\begin{array}{l}\text { Home language } \\
\text { proficiency }\end{array}$ & $\begin{array}{l}.44 \\
* *\end{array}$ & .13 & $\begin{array}{l}.59 \\
* *\end{array}$ & .29 & $\begin{array}{l}.42 \\
* *\end{array}$ & 1 & & & & & & & & & & \\
\hline Total & $\begin{array}{l}.94 \\
* *\end{array}$ & $\begin{array}{l}.32 \\
* *\end{array}$ & .73 & $\begin{array}{l}.80 \\
* *\end{array}$ & $\begin{array}{l}.79 \\
* *\end{array}$ & $\begin{array}{l}.56 \\
* *\end{array}$ & 1 & & & & & & & & & \\
\hline $\begin{array}{l}\text { Withdrawn } \\
\text { /depressed }\end{array}$ & $\begin{array}{l}-.36 \\
* *\end{array}$ & $\begin{array}{l}-.31 \\
* *\end{array}$ & $\begin{array}{l}-.25 \\
* *\end{array}$ & $\begin{array}{l}-.26 \\
* *\end{array}$ & $\begin{array}{l}-.31 \\
* *\end{array}$ & -.09 & $\begin{array}{l}-.38 \\
* *\end{array}$ & 1 & & & & & & & & \\
\hline Anxious /depressed & $\begin{array}{l}-.19 \\
* *\end{array}$ & -.12 & -.09 & $\begin{array}{l}-.20 \\
* *\end{array}$ & $\begin{array}{l}-.24 \\
* *\end{array}$ & -.04 & $\begin{array}{l}-.23 \\
* *\end{array}$ & $\begin{array}{l}.55 \\
* *\end{array}$ & 1 & & & & & & & \\
\hline Social problems & $\begin{array}{l}-.43 \\
* *\end{array}$ & -.09 & $\begin{array}{l}-.23 \\
*\end{array}$ & $\begin{array}{l}-.53 \\
* *\end{array}$ & $\begin{array}{l}-.37 \\
* *\end{array}$ & -.08 & $\begin{array}{l}-.45 \\
* *\end{array}$ & $\begin{array}{l}.42 \\
* *\end{array}$ & $\begin{array}{l}.52 \\
* *\end{array}$ & 1 & & & & & & \\
\hline Thought problems & $\begin{array}{l}-.36 \\
* *\end{array}$ & -.04 & $\begin{array}{l}-.25 \\
* *\end{array}$ & $\begin{array}{l}-.40 \\
*\end{array}$ & $\begin{array}{l}-.35 \\
* *\end{array}$ & -.17 & $\begin{array}{l}-.41 \\
* *\end{array}$ & .54 & $\begin{array}{l}.49 \\
* *\end{array}$ & $\begin{array}{l}.55 \\
* *\end{array}$ & 1 & & & & & \\
\hline Attention problems & $\begin{array}{l}-.73 \\
* *\end{array}$ & .12 & $\begin{array}{l}-.38 \\
* * *\end{array}$ & $\begin{array}{l}-.74 \\
* *\end{array}$ & $\begin{array}{l}-.53 \\
* *\end{array}$ & $\begin{array}{l}-.36 \\
* * *\end{array}$ & $\begin{array}{l}-.71 \\
* *\end{array}$ & $\begin{array}{l}.33 \\
* *\end{array}$ & $\begin{array}{l}.32 \\
* *\end{array}$ & $\begin{array}{l}.55 \\
* *\end{array}$ & $\begin{array}{l}.43 \\
* *\end{array}$ & 1 & & & & \\
\hline Delinquent behavior & $\begin{array}{l}-.47 \\
* *\end{array}$ & .15 & $\begin{array}{l}-.21 \\
* * *\end{array}$ & $\begin{array}{l}-.56 \\
* *\end{array}$ & $\begin{array}{l}-.30 \\
* *\end{array}$ & -.08 & $\begin{array}{l}-.45 \\
* *\end{array}$ & .21 & .20 & $\begin{array}{l}.46 \\
* *\end{array}$ & .26 & .71 & 1 & & & \\
\hline Aggressive behavior & $\begin{array}{l}-.44 \\
* *\end{array}$ & $\begin{array}{l}.28 \\
* *\end{array}$ & -.12 & $\begin{array}{l}-.71 \\
* *\end{array}$ & $\begin{array}{l}-.35 \\
* *\end{array}$ & -.16 & $\begin{array}{l}-.48 \\
* *\end{array}$ & .29 & $\begin{array}{l}.36 \\
* *\end{array}$ & $\begin{array}{l}.65 \\
* *\end{array}$ & $\begin{array}{l}.46 \\
* *\end{array}$ & $\begin{array}{l}.74 \\
* *\end{array}$ & .67 & 1 & & \\
\hline Externalizing & $\begin{array}{l}-.48 \\
* *\end{array}$ & $\begin{array}{l}.27 \\
* *\end{array}$ & -.16 & $\begin{array}{l}-.71 \\
*\end{array}$ & $\begin{array}{l}-.36 \\
* *\end{array}$ & -.15 & $\begin{array}{l}--.50 \\
* *\end{array}$ & .28 & $\begin{array}{l}.34 \\
* *\end{array}$ & $\begin{array}{l}.64 \\
* *\end{array}$ & $\begin{array}{l}.44 \\
* *\end{array}$ & $\begin{array}{l}.78 \\
* *\end{array}$ & .81 & $\begin{array}{l}.87 \\
* *\end{array}$ & 1 & \\
\hline Internalizing & $\begin{array}{l}-.28 \\
* *\end{array}$ & $\begin{array}{l}-.23 \\
*\end{array}$ & -.12 & $\begin{array}{l}-.23 \\
*\end{array}$ & $\begin{array}{l}-.29 \\
* *\end{array}$ & -.03 & $\begin{array}{l}-.30 \\
* *\end{array}$ & $\begin{array}{l}.79 \\
* *\end{array}$ & $\begin{array}{l}.88 \\
* *\end{array}$ & $\begin{array}{l}.47 \\
* *\end{array}$ & $\begin{array}{l}.47 \\
* *\end{array}$ & $\begin{array}{l}.40 \\
* *\end{array}$ & $\begin{array}{l}.23 \\
*\end{array}$ & $\begin{array}{l}.40 \\
*\end{array}$ & $\begin{array}{l}.38 \\
* *\end{array}$ & 1 \\
\hline
\end{tabular}

Note: $* * \mathrm{p}<.01, * \mathrm{p}<.05$ 
with executive functioning. Findings here support research indicating that deficits in children's literacy skills are linked to behaviour problems (Arnold, 1997; Lonigan, Bloomfield, \& Anthony, 1999). Column 5 indicates that the educational support/intervention variable was statistically significantly and negatively related to each of the nine subscales on the TRF, with small to very large effect sizes. Column 6 demonstrates that the home language proficiency subscale was statistically significantly and negatively related to the attention problems subscale on the TRF, corresponding to medium effect sizes. That is, more proficiency in a home language was related to having fewer of the behaviours associated with attention problems in the classroom. Column 7 indicates that the total or overall score of children's social and emotional and academic learning was statistically significantly and negatively correlated to each of the seven TRF subscales and two overarching domains, corresponding to medium to large effect sizes. No additional statistically significant relationships were observed between the variables.

Overall, the correlations presented in rows two through nine confirm (a) that the findings in Study 1, that the majority of CLDQ variables were statistically significant and positive, and that the magnitude of the effects were medium to large, and (b) that the CLDQ variables and the TRF variables indicate primarily statistically significant and negative relationships, with medium to large effect sizes, providing evidence of convergent validity for the CLDQ. In other words, children who were rated by teachers as having high levels of social and emotional development and academic learning on the CLDQ subscales had low scores for clinical maladjustment on the TRF subscales.

\section{Discussion}

The goal of Study 2 was to understand whether the six components/subscales that comprise the CLDQ were related to the Achenbach TRF subscales. Results confirmed that the CLDQ ratings were negatively related to the Achenbach TRF ratings and provide evidence of convergent validity, indicating that the six subscales/components extracted from the CLDQ are related to the seven subscales and two overarching domains of the TRF. Findings demonstrated that when the CLDQ indicates that a child is displaying adaptive social and emotional development and academic learning, the TRF ratings correlate with this and do not register clinically signifi- cant social and emotional maladjustment and academic difficulties.

\section{Conclusions and Future Directions}

The studies presented here provide evidence that the CLDQ demonstrates fair levels of reliability and validity for assessing six individual level risk and protective factors related to typically developing children's social and emotional development and academic learning in elementary school: namely, respect/compliance, classroom learning/achievement, proficiency in English, temperament/disposition, educational support/intervention, and home language proficiency. Moreover, results provide evidence indicating that teachers can provide reliable and valid ratings about children's behaviour related to their social and emotional development and academic learning in school.

These findings would lead us to view the CLDQ as useful to educators, within the North American context, as a source of information to guide understandings of children's behaviour related to their social and emotional development and academic learning. With continued validation of the psychometric properties of the CLDQ, this measure may be used to assist in guiding teachers and school psychologists to understand and implement strategies for supporting children through individual and contextual interventions and/or through clinical referrals.

Caution should be used when interpreting the results of this study. The strength of Study 1 is that results were obtained from a large sample of children $(N=820)$. One of the limitations of Study 1 was that a significant amount of data was missing on the sex of children and could not examine the relationships between the extracted components and sex. This will need to be addressed in future research. Study 2 confirmed the relationships between the CLDQ variables observed in Study 1 and provided evidence of convergent validity, whereby the CLDQ subscales were significantly and negatively related to the TRF subscales. A limitation of Study 2 was that it had a smaller sample of children $(N=117)$, so research confirming these results would be beneficial.

Together, results of the studies indicate that the CLDQ identified two additional risk and protective factors: specifically, students' abilities to use language, as in their English proficiency and their home language proficiency. Schools are increasingly multicultural contexts, so having insight into children's abilities to use language is an important considera- 
tion for researchers when studying social and emotional development and academic learning. Based on our results, we recommend developing additional measures for the English language and home language proficiency subscales, to increase knowledge about the ways language learning is related to children's development and learning in school. A final limitation of this research was that only one form of data was gathered to capture information about children's behaviour: namely, teacher reports. We recommend that future research continue validating this measure by triangulating the CLDQ with other measures and types of data (e.g., contextual data) in order to provide a richer understanding of children's behaviour in context.

\section{Implications for School System Practice}

The CLDQ has shown itself to be a universal screening form that encompasses key dimensions of the essential educational services in any school system. The items included in the checklist were identified and nominated by educators, teachers, and practitioners from five allied disciplines, including speech and language pathology, school psychology, school social work/school counselling, learning assistance/reading services, child and adolescent psychiatry, and English language specialization; all of them were core members in the school support teams. The CLDQ rating form identifies areas of strength and needs while also providing a comprehensive multidimensional profile for students. Based on the comprehensive profile, the teachers may readily set priorities for student referrals to activate in-class (Tier 1) and in-school resources (Tier $1 \&$ Tier 2).

The CLDQ rating scale is in line with the multilingual, multicultural reality of the regular classroom in North American education system. The language of instruction, academic achievement levels, and the role of the student's linguistic and cultural heritage are given equal emphasis.

As a cost-effective, comprehensive, multidimensional profile, the CLDQ lends itself easily to integrative service delivery schemas at the individual student and classroom level. The form takes 5-10 minutes for the classroom teacher to complete. Teachers who have responded to it in the studies to date have found the questionnaire easy to use. In post-study discussions, teachers have applauded the ease of questionnaire completion and its usefulness in describing each student's attributes within the school context. The questionnaire helped provide educators with a shared language for ease in collegi- al and school-to-home communication. Items have helped give voice to teachers' concerns and have been used in consultations with school-based support services and in secondary referrals to special services and/or clinical assessments. The comprehensive multi-dimensional profile enabled the educators and support services to engage relevant professional disciplines in early identification and preventive measures to enhance student achievement and adaptive functioning. The use of the form did support consultation and collaboration with parents for primary prevention at the classroom level.

At the system level, front line practitioner concerns are easily brought forward in a systematic fashion, offering data for resource allocation decisions, school monitoring, and an evidence-based guide to further interpret other standardized information currently available. In this fashion, the CLDQ provides reliable data for evaluation of school programs and planning for school improvement and student success.

As an initial screening tool, the CLDQ may be used to provide a new dimension to school district level monitoring and intervention. The information contained in the assessments is based on observations made by teachers at the school level. It may provide district administration with the opportunity to respond to factors that can influence the learning context at the school. The data derived from the CLDQ may be used to guide and support districtwide efforts for early interventions for all children. Data may be easily gathered in both a cross-sectional and longitudinal fashion to track children's social and emotional development and academic learning trajectories and profiles. This undertaking would be of great benefit to school districts as they monitor supports allocated to schools. Further, such a measure offers early impetus to modify children's educational programming to respond to their individual needs. With respect to staff development, children's social and emotional development and learning profiles, which emerge from the CLDQ, can provide data to help districts support teachers' professional development needs.

Most children attend school, and teachers observe their behaviour on a daily basis. The school is often the starting point for the involvement of the other social service partners, including social workers, speech/hearing specialists, educational psychologists and clinical psychiatrists. The CLDQ may be used to provide information for school-based learning teams as they plan school-wide tasks and activities for individual children and for their class- 
rooms. Data from the CLDQ may help teachers to seek out preventative and early interventions for their students and help them to prioritize school resources and involve additional system-wide supports for children. The data from the CLDQ can provide insight into individual growth profiles for children and, over time, trajectories of children's social and emotional development and academic learning. This tool is quite applicable to determining interventions and monitoring their progress.

With subsequent development and continued validation, the CLDQ can provide school psychologists with an inexpensive and early screening tool for understanding individual-level risk and protective factors related to typically developing children's social and emotional development and academic learning. Data can give school psychologists and mental health professionals insight into children's individual-level functioning across a number of factors, and it can (in part) be used to guide interventions and supports for children, with a view to reducing or modulating their trajectory of risk toward further social, emotional, and academic difficulties. Also, by implementing this measure as a screening tool, primary prevention programs, rather than clinical interventions, can be initiated by school psychologists working with teachers, so that children's social and emotional development and academic learning can be supported over the long term. As in classroomlevel interventions, allied health professionals can use this tool as a measure for pre-emptive intervention and as an indicator of progress toward resolution of concerns. The Classroom Learning Development Questionnaire (CLDQ) provides an effective and succinct tool to support the learning and development needs of children in a cost-effective manner. It provides a valuable support to school systems working with limited resources in the modern context.

Interestingly, the screening tool presented in this paper was first developed in a Canadian school system, subsequently adapted to an Asian context, and finally reintroduced to a North American context. The screening tool, in its Asian format, has been fully incorporated into the school system in Hong Kong, with associated research and program development. The time has arrived for North American practitioners to learn from our Asian confreres and to re-adapt their programming initiatives to the North American educational environment.

\section{Note}

1. Before interpreting the components in the principal component analysis (PCA), we compared the PCA with an exploratory factor analysis (EFA) (Suhr, n.d.) with maximum likelihood estimation. Results of the second factor analysis also suggested the extraction of six components, and explained 67.49 percent of the variance among the variables.

\section{References}

Achenbach, T.M. (1991). Manual for the teacher's report form and 1991 profile. Burlington, VT: University of Vermont Department of Psychiatry.

Achenbach, T.M., \& Rescorla, L.A. (2001). Manual for the ASEBA school-age forms \& profiles. Burlington, VT: University of Vermont Research Center for Children, Youth, \& Families.

Albee, G.W. (2004). Historical overview of primary prevention of psychopathology: Invited address to the Third Biennial World Conference on the Promotion of Mental Health and Prevention of Mental and Behavioral Disorders, September 15-17, 2004, Auckland, New Zealand. The Journal of Primary Prevention, (27) 5, 449-456.

American Psychiatric Association. (1994). Diagnostic Interview Schedule for Children Version 2.3.

Amato, P.R. (2004). The consequences of divorce for adults and children. Journal of Marriage and Family, 62, 1269-1287.

Arnold, D.H. (1997). Co-occurrence of externalizing behavior problems and emergent academic difficulties in young high-risk boys: A preliminary evaluation of patterns and mechanisms. Journal of Applied Developmental Psychology, 18, 317-330.

Avison, W.R. (1996). Social networks as risk and protective factors for onset and recurrence of mental disorders. Current Opinion in Psychiatry, 9, 192-206.

Breakthrough. (1993). A report of the study on the value orientation and the tendency to selfdestroy among secondary school students in Hong Kong [in Chinese]. Hong Kong: Breakthrough Limited.

Burchinal, M.R., Peisner-Feinberg, E., Pianta, R., Howes, C. (2002). Development of academic skills from preschool through second grade: Family and classroom predictors of developmental trajectories. Journal of School Psychology, 40, 415-436. 
Burchinal, M.R., Roberts, J.E., Zeisel, S.A., \& Rowley, S.J. (2008). Social risk and protective factors for African American children's academic achievement and adjustment during the transition to middle school. Developmental Psychology, 44, 286-292.

Catalano, R.F., Hill, K.G., Haggerty, K.P., Fleming, C.B., \& Hawkins, J.D. (2010). Chapter 5: Social development interventions have extensive longlasting effects. In A.E. Fortune, P. McCallion, \& K. Briar-Lawson (Eds.), Social work practice research for the 21st century (pp. 72-80). New York: Columbia University Press.

Catalano, R.F., Mazza, J.J., Harachi, T.W., Abbott, R.D., Haggerty, K.P., \& Fleming, C.B. (2003). Raising healthy children through enhancing social development in elementary school: Results after 1.5 years. Journal of School Psychology, 41, 143-164.

Compte, B., Fleisher, W., Wand, R., Oborne, D., \& Hoh, Y. (1997). Hong Kong youth-at-risk project. The Canadian Child Psychiatric Review, 6, 10-16.

Coplan, R.J., DeBow, A., Schneider, B.H., \& Graham, A.A. (2009). The social behaviours of inhibited children in and out of preschool. British Journal of Developmental Psychology, 27, 891-905.

Cummings, E.M., \& Davies, P.T. (2002). Effects of marital conflict on children: Recent advances and emerging themes in process-oriented research. Journal of Child Psychology and Psychiatry, 43, 31-63.

Cummins, J. (2000). Language, power, and pedagogy: Bilingual children in the crossfire. Clevedon, UK: Multilingual Matters.

Doll, B., \& Lyon, M.A. (1998). Risk and resilience: Implications for the delivery of educational and mental health services in school. School Psychology Review, 27, 348-363.

Dryfoos, J. (1998). Safe passage: Making it through adolescence in a risky society. New York, NY: Oxford University Press.

Education Bureau, Hong Kong. (2013). Understanding the Adolescent Project. Circular Memorandum No.19, March 4, 2013. Retrieved August 19, 2013, from http://www.edb.gov.hk/.../projects... /understanding-adolescent-project.../EDB...
Education Bureau, Hong Kong. (2013). Understanding the Adolescent Project (Primary). Hong Kong Student Information Form (HKSIF), 2006 to current. Retrieved June 19, 2013, from http://www.edb.gov.hk/.../projects.../understandin g-adolescent-project.../edbc

El-Sheikh, M., \& Whitson, S.A. (2006). Longitudinal relations between marital conflict and child adjustment: Vagal regulation as a protective factor. Journal of Family Psychology, 20, 30-39.

Fraser, M.W., Day, S.H., Galinsky, M., Hodges, V., \& Smokowski, P.R. (2004). Conduct problems and peer rejection in childhood: A randomized trial of the Making Choices and Strong Families programs. Research on Social Work Practice, 14, 313-324.

Gladstone, T.R., \& Kaslow, N.J. (October, 1995). Depression and attributions in children and adolescents: A meta-analytic review. Journal of Abnormal Child Psychology, Volume 23, Issue 5, 597-606.

Grant, E. (2003). Results of the community mapping study for children in Fraser North, BC. Unpublished report for Human Resource Development Canada.

Graziano, P.A., Reavis, R.D., Keane, S.P., \& Calkins, S.D. (2007). The role of emotion regulation in children's early academic success. Journal of School Psychology, 45, 3-19.

Hamre, B.K., \& Pianta, R.C. (2005). Can instructional and emotional support in the first grade classroom make a difference for children at risk for school failure? Child Development, 76, 949-967.

Hawkins, J.D., Catalano, R.F., Kosterman, R., Abbott, R.D., \& Hill, K.G. (1999). Preventing adolescent health-risk behaviors by strengthening protection during childhood. Archives of Pediatrics and Adolescent Medicine, 153, 226-254.

Hawkins, J.D., Catalano, R.F., Morrison, D.M., O’Donnell, J., Abbott, R.D., \& Day, L.E. (1992). The Seattle social development project: Effects of the first four years on protective factors and problem behaviors. In $\mathrm{J}$. McCord \& R.E. Tremblay (Eds.), Preventing adolescent antisocial behavior: Interventions from birth through adolescence (pp. 139-161). New York: Guildford Press.

Hay, D.F., \& Pawlby, S. (2003). Prosocial development in relation to children's and mothers' psychological problems. Child Development, 74, 1314-1327. 
Hetherington, E.M., \& Stanley-Hagan, M. (1999). The adjustment of children with divorced parents: A risk and resiliency perspective. The Journal of Child Psychology and Psychiatry and Allied Disciplines, 40, 129-140.

Hsieh, M.O., \& Shek, D.T. (2008). Personal and family correlates of resilience among adolescents living in single-parent households in Taiwan. Journal of Divorce and Remarriage, 49, 330-348.

Huck, S.W. (2008). Reading statistics and research (5th ed.). New York: Pearson.

Kessler, M., \& Albee, G.W. (1975). Primary prevention. Annual Review of Psychology, 26, 557-591.

Lane, K.L., Beebe-Frankenberger, M.E., Lambros, K.M., \& Pierson, M. (2001). Designing effective interventions for children at risk for antisocial behavior: An integrated model of components necessary for valid inference making. Psychology in the Schools, 38, 365-379.

Lau, J. (2003). Report on evaluation of the Understanding the Adolescent Project (UAP) in secondary schools 2001/2002. Hong Kong: Chinese University of Hong Kong.

Lau, J.T.F., Choi, P.Y.W., Lai, K.Y.C., Chan, K.K., Oborne, D.W., Cheng Ho, Y.C., Wand, R., \& Comte, B. (1999). A new instrument for large-scale screening of potentially "at risk" secondary school students in Hong Kong. Hong Kong: Centre for Clinical Trials and Epidemiological Research, Faculty of Medicine, Chinese University of Hong Kong.

Lee, T.Y. (2007). Chinese approaches to understanding and building resilience. Child and Adolescent Clinics of North America, 16(2), 377-392.

Leventhal, T., \& Brooks-Gunn, J. (2000). The neighborhoods they live in: The effects of neighborhood residence upon child and adolescent outcomes. Psychological Bulletin, 126, 309-337.

Lonigan, C.J., Bloomfield, B.G., \& Anthony, J.L. (1999). Relations among emergent literacy skills, behavior problems, and social competence in preschool children from low- and middle-income backgrounds. Topics in Early Childhood Special Education, 62, 40-53.

Meece, J., Anderman, E.M., \& Anderman, L. H. (2006), Classroom goal structure, student motivation, and academic achievement. Annual Review of Psychology, 57, 505-528.
Miller, J. (2009). Teaching refugee learners with interrupted education in science: Vocabulary, literacy, and pedagogy. International Journal of Science Education, 31, 571-592.

Nagin, D.S., \& Tremblay, R.E. (2001). Parental and early childhood predictors of persistent physical aggression in boys from kindergarten to high school. Archives of General Psychiatry, 58, 389-394.

Oborne, D.W. (2001). A New Form for Socialemotional screening for Adolescents. Presentation to the Annual Conference of the Canadian Paediatric Association. Vancouver, BC: Canadian Paediatric Association.

Oborne, D.W., \& Cheng Hoh, Y. (1990). Reaching out to Asian youth: The Winnipeg experience. In Wayne Holtman (Ed.), Mental health of immigrants and refugees. Austin, TX: The Hogg Foundation \& University of Texas.

Oborne, D.W., \& Cheng Hoh, Y. (1996). The Understanding the Adolescent Project research report. Unpublished presentation to the Joint Committee on Health and Welfare. Hong Kong: Breakthrough Limited.

Oborne, D.W. \& Cheng Hoh, Y. (2000). Presentation to the Shanghai Education Authority. "Screening for 'At Risk" Adolescents" Shanghai, China

Oborne, D.W. \& Cheng Hoh, Y. (2000). Screening for "At Risk Adolescents." Presentation to the Calgary Regional Health Authority. Calgary, AB: Calgary Regional Health Authority.

Offord, D.R., Alder, R.J., \& Boyle, M.H. (1986). Prevalence and sociodemographic correlates of conduct disorder. American Journal of Social Psychiatry, 6, 272-278.

Rae-Grant, N.I., Thomas, B.H., Offord, D.R., \& Boyle, M.H. (1989). Risk, protective factors and the prevalence of behavioral and emotional disorders in children and adolescents. Journal of the American Academy of Child and Adolescent Psychiatry, 28, 262-268.

Roessingh, H. (2004). Effective high school ESL programs: A synthesis and meta-analysis. Canadian Modern Language Review, 60(5), 611-636.

Roessingh, H., \& Elgie, S. (2009). Early language and literacy development among young English language learners: Preliminary insights from a longitudinal study. TESL Canada Journal/Revue TESL du Canada, 26(2), 24-45. 
Rouse, H., \& Fantuzzo, J. (2009). Multiple risks and educational well being: A population-based investigation of threats to early school success. Early Childhood Research Quarterly, 24(1), 1-14.

Rutter, M. (1979). Protective factors in children's responses to stress and disadvantage. In J.S. Bruner \& A. Garten (Eds.), Primary prevention of psychopathology, Vol. 3 (pp. 49-74). Hanover, NH: University Press of New England.

Rutter, M. (2001). Psychosocial adversity: Risk, resilience, and recovery. In J.M. Richman \& M.W. Fraser (Eds.), The context of youth violence: Resilience, risk, and protection (pp. 1341). Westport, CT: Praeger Publishers.

Rutter, M., \& Quinton, D. (1975). Attainment and adjustment in two geographical areas: III - some factors accounting for area differences. The British Journal of Psychiatry, 126, 520-533.

Rutter, M., \& Quinton, D. (1984). Parental psychiatric disorder: Effects on children. Psychological Medicine, 14, 853-880.

Sameroff, A., Seifer, R., Zax, M., \& Barocas, R. (1987). Early indicators of developmental risk: Rochester longitudinal study. Schizophrenia Bulletin, 13, 383-394.

Shumow, L., Vandell, D.L., \& Posner, D. (1999). Risk and resilience in the urban neighborhood: Predictors of academic performance among low-income elementary school children. Merrill-Palmer Quarterly, 45, 309-331.

Smokowski, P.R., Mann, E., Reynolds, W.M., \& Fraser, M.W. (2004). Longitudinal relationships among childhood risk and protective factors and late adolescent adjustment domains: Evidence from the Chicago longitudinal study. Children and Youth Services Review, 26, 63-91.

SRDC. (2005, Fall). Learning What Works: Understanding the Early Years, 5(2).

Statistics Canada. (2006). Census data. Retrieved August 21, 2013 from http://www12.statcan.gc .ca/census-recensement/2006/dppd/prof/92591 $/$ details/page.cfm?B1 $=$ All\&Code $1=5915034 \&$ Co de $2=59 \&$ Custom $=\&$ Data $=$ Count $\&$ Geo $1=$ CSD $\&$ Geo2=PR\&Lang $=$ E\&SearchPR $=01 \&$ SearchText $=$ Coquitlam $\&$ SearchType $=$ Begins
Suhr, D. (n.d.). Principal component analysis vs. exploratory factor analysis. Paper 203-30. University of Northern Colorado. Retrieved August 20, 2013 from http://www2.sas.com/proceedings/ sugi30/203-30.pdf

Teo, A., Carlson, E., Mathieu, P.J., Egeland, B., \& Sroufe, L.A. (1996). A prospective longitudinal study of psychosocial predictors of academic achievement. Journal of School Psychology, 34, 285-306.

Thomas, W.P., \& Collier, V.P. (2002). A national study of school effectiveness for language minority students' long-term academic achievement. Santa Cruz: University of California, Center for Research on Education, Diversity, and Excellence.

Tung Chee Hwa. (2000, October 11). Serving the community, sharing common goals. Policy address to Hong Kong Legislative Council.

Walker, H.M., Stiller, B., Severson, H.H., Feil, E.G., \& Golly, A. (1998). First step to success: An effective preventative intervention for antisocial behavior in primary grades. Psychology in the Schools, 35, 259-269.

Waller, M.A. (2001). Resilience in ecosystematic context: Evolution of the concept. American Journal of Orthopsychiatry, 71, 290-297.

Wentzel, K.R. (1993a). Does being good make the grade? Social behavior and academic competence in middle school. Journal of Educational Psychology, 85, 357-364.

Wentzel, K.R. (1993b). Motivation and achievement in early adolescence: The role of multiple classroom goals. Journal of Early Adolescence, 13, 4-20.

Werner, E., \& Smith, R. (1989). Vulnerable but invincible: A longitudinal study of resilient children and youth. New York, NY: Adams, Bannister, and Cox.

Werner, E., \& Smith, R. (1992). Overcoming the odds: High-risk children from birth to adulthood. New York, NY: Cornell University Press.

Wong, K. \& Lee, T. (2005). Professional discourse of social workers working with at-risk young people in Hong Kong: Risk or resilience. In M. Ungar (Ed.), Handbook for working with children and youth: Pathway to resilience across cultures (pp. 313-32). Thousand Oaks, CA: Sage Publications, Inc.

IJEPL is a joint publication of PDK International, the Faculty of Education at Simon Fraser University and the College of Education and Human Development at George Mason University. By virtue of their appearance in this open access journal, articles are free to use, with proper attribution, in educational and other non-commercial settings 90 days after initial publication. Copyright for articles published in IJEPL is retained by the authors. More information is available on the IJEPL Web site: http://www.ijepl.org 